\title{
1. China's Path Towards New Growth: Drivers of Human Capital, Innovation and Technological Change
}

\section{Ligang Song, Cai Fang and Lauren Johnston ${ }^{1}$}

\section{Introduction}

Since the last China Update volume, sluggish world growth, of a touch above 3 per cent in 2016, has added to concerns about China's financial sector and sustainable growth prospects at least in the near term. Geopolitical shocks in the United States and United Kingdom have exaggerated the uncertainty around whether China will be able to navigate away from an export, capital and resourceintensive growth model towards a new model of economic growth.

In the 2016 book, we covered China's economy from the perspectives of reform, energy and resources and climate change as volume one. This year's book explores topics in China's progress in advancing the new growth frontiers of human capital, innovation and technological change.

The new growth path that China seeks to tread is broadly that followed by today's advanced economies in earlier times. It involves substitution of intangibles such as innovation and technology for tangible components of factors of production such as land, labour and physical capital (Maddison 1982). Many countries, however, get stuck in that transition and fail over decades in their attempt to enter the highincome group - a circumstance known as the 'middle-income trap' (Eichengreen et al. 2013).

For China, the transition towards new, advanced-economy growth drivers offers a route to continued economic development. It means relying less on industries that are resource- and pollution-intensive, such as steel and construction, and on labourintensive and low-quality manufacturing. It means instead shifting the growth model towards consumption, services, higher value-added manufacturing and innovation. China has already made significant progress towards the development of new high-tech industries in high-speed rail (HSR) transportation, ${ }^{2}$ high value-added

1 We thank Shenglang Yang for his help with assembling the data used in this chapter.

2 The total length of China's high-speed rail reached 12,000 km in 2016. 
manufacturing including super-fast quantum computing, aviation ${ }^{3}$ and space technologies. ${ }^{4}$ It has similarly made progress in reducing the adverse environmental spillovers of the economy and fostering high-tech manufacturing-not least by becoming a world leader in new-energy technology including solar panels, wind turbines, hybrid cars and new materials.

This year's book takes a closer look at the role of human capital, innovation and technological change in affecting the pattern of growth and general development of the Chinese economy. First, we explore recent macroeconomic developments, alongside trends in education and innovation. We also look at how structural change is preparing the economy for a more advanced set of economic growth drivers.

\section{Macroeconomic development}

China's economy is now growing at a consistently slower 'new normal' rate than the double-digit growth of the first decade or so of this century. Nonetheless, it continues to grow faster than all other major economies. Figure 1.1 shows that the Chinese economy grew at 6.7 per cent in 2016, and illustrates the persistent growth deceleration. The slowdown is causing immense overcapacity problems in some industries. Overcapacity has to be managed alongside major challenges of uncertainty about the nature of contemporary change and the risks and problems of inequality of access in the financial sector.

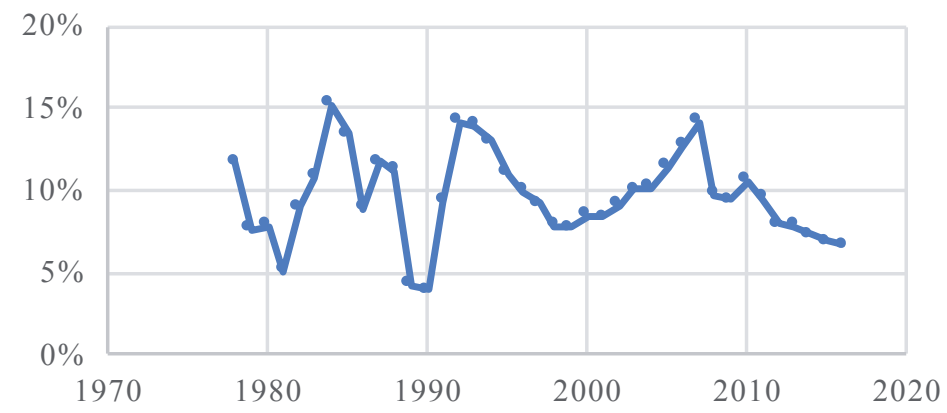

Figure 1.1 GDP growth rates, 1975-2016

Source: NBS (various years).

3 China's first commercial jet aircraft (C919) conducted its first test flight on 5 May 2017.

4 This includes the prospect that China will own and operate the world's only space station from 2022. 
China has made progress in recent years in rebalancing the economy towards household consumption and away from fixed capital investment (Figure 1.2).

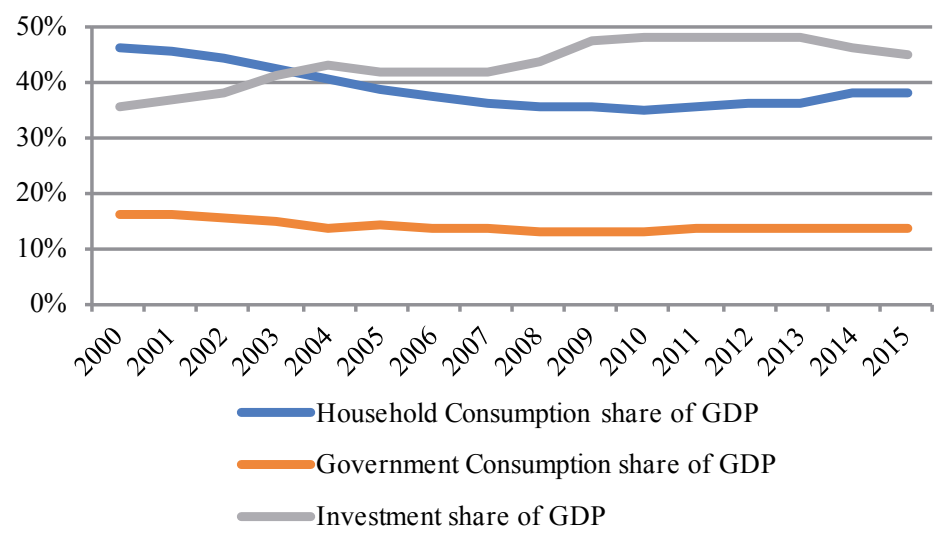

Figure 1.2 Consumption and investment, 2000-15

Source: NBS (various years).

As required by China's new model of growth, the tertiary sector has continued to increase its relative size, accounting for 52 per cent of gross domestic product (GDP) in 2016, while secondary ( 40 per cent share in 2016) and primary ( 8 per cent) industries have continued their relative decline (Figure 1.3).

China's new growth model allocates a lesser place for exports as a driver of growth. Over the first 30 years of reform, China benefited from a more favourable trading environment. The share of exports in China's GDP rose from about 5 per cent in 1980 to a peak of 37 per cent in 2006 (Figure 1.4), but has fallen since.

China became the largest trading nation in the world, surpassing the United States, in 2013 and has retained that status since.

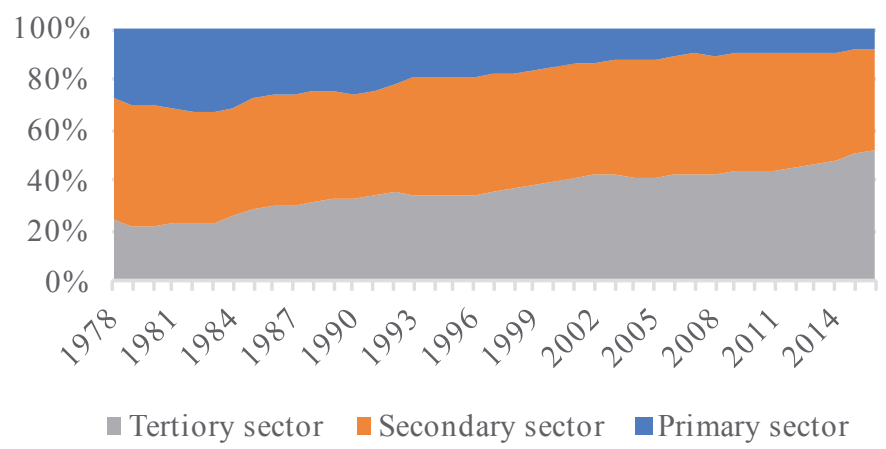

Figure 1.3 Sector shares in total GDP, 1978-2016

Source: NBS (various years). 


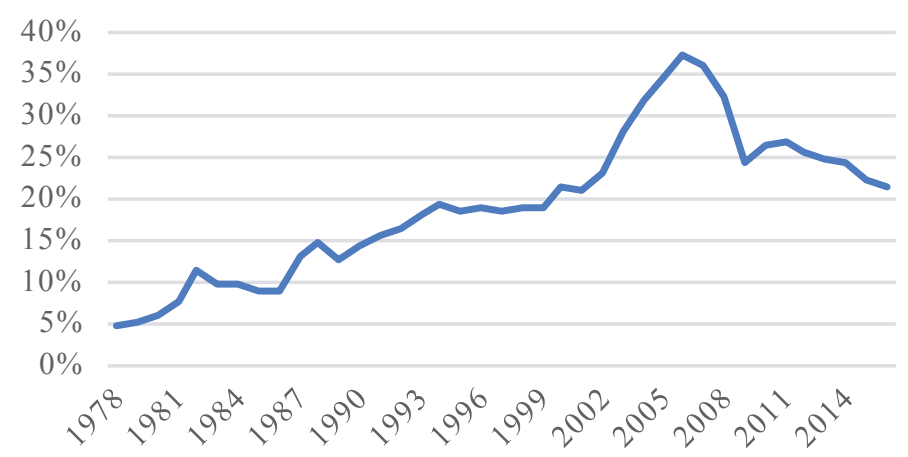

Figure 1.4 China's export share in GDP, 1978-2016

Source: NBS (various years).

Consistent with the new model of growth, China's trade surpluses have fallen as shares of GDP (Figure 1.5). China's total foreign reserves have also fallen considerably, to about US\$3 trillion in 2016. After a long period of currency appreciation and pressure for more, in recent years, the pressure has now been for renminbi (RMB) depreciation against the US dollar.

The decline in Chinese trade surpluses has eased global imbalances; however, reduced export orientation of the Chinese economy has contributed to the deceleration of global trade growth. Developments in China have been a major factor in the decline of trade in global economic activity since 2012.

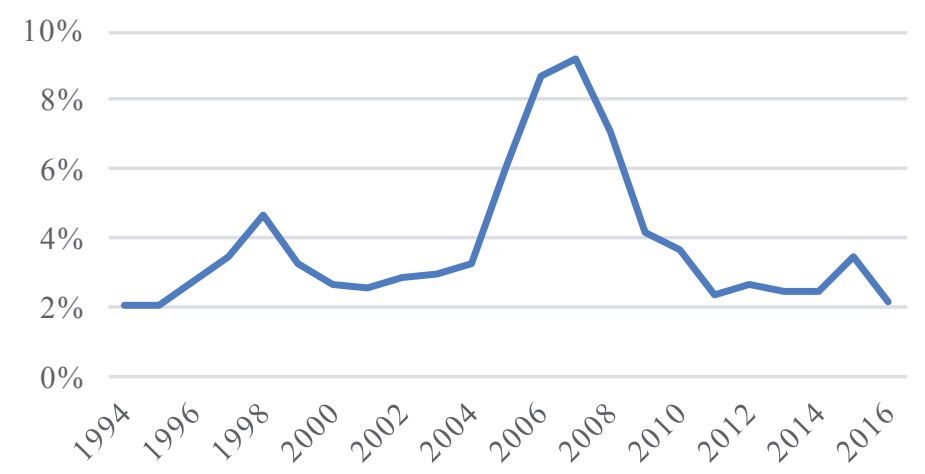

Figure 1.5 Share of China's trade surpluses in GDP, 1994-2016 Source: NBS (various years).

China's share of global trade grew more rapidly than its share of output until the Global Financial Crisis (GFC), but more slowly since (Figure 1.6). 


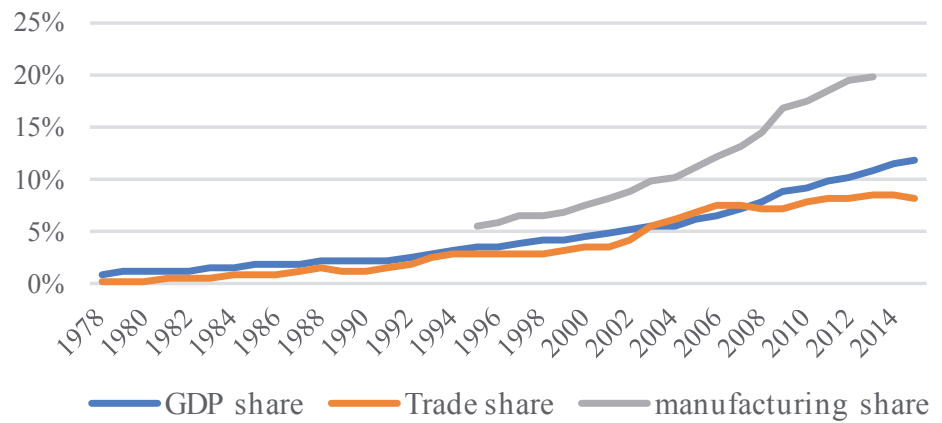

Figure 1.6 Shares of China's GDP and trade in global totals, 1978-2014 (2010 constant US\$)

Sources: World Bank (databank.worldbank.org/data/home.aspx) and NBS (various years).

Data from The Conference Board (2015) show a modest increase in total factor productivity (TFP) growth in 2015 after several years of stagnation. According to some estimates, the contribution of TFP to China's economic growth has fallen consistently since 2008 (Figure 1.7). This may be explained by the massive increase in investment through the fiscal stimulus package that was a response to the GFC and which was associated with a large decline in returns to capital. The decline in the labour force in recent years and the lower rate of urbanisation have also contributed to higher capital/labour ratios and lower capital productivity growth. The share of people of working age in the population has been falling since 2012 .

These factors are behind the rising imperative for China to find new ways to boost productivity.

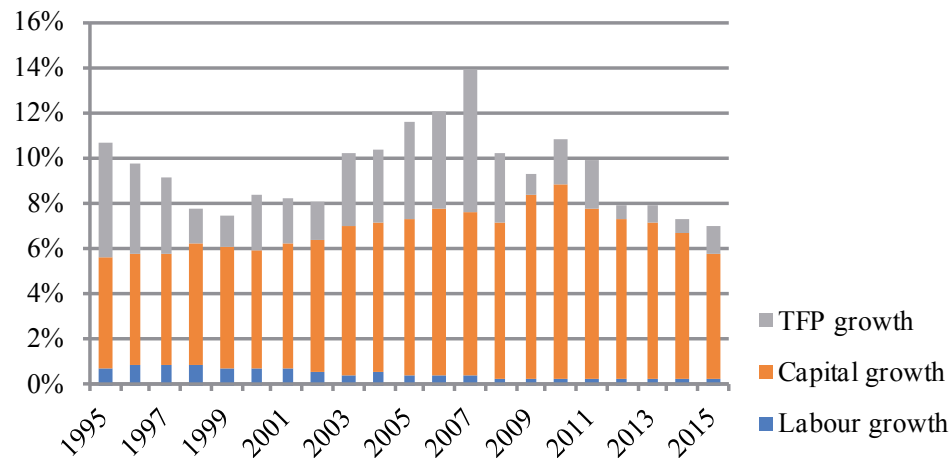

Figure 1.7 Decomposition of China's GDP growth, 1995-2015 Note: Growth is calculated as a log-difference.

Source: The Conference Board (2015). 
China has made strides over recent decades in developing its human capital, its innovative capacities and technological potential. Transforming these into growth drivers that allow China to climb through the middle-income trap into the highincome group of countries depends on how resources of all kinds are allocated to the most productive uses. This requires structural reform.

Structural reform within China's new model of growth has been highlighted in most recent China Update books. This year's book concentrates on human capital, innovation and technology.

\section{Human capital}

Improvements in education and skills can considerably increase the productivity and earnings of labour. But the capacity to absorb and use physical capital may be limited by, among other things, investment in human capital. There may thus be a close association between education and the mainsprings of technological progress (Thirlwall and Pacheco-Lopez 2017: 210).

Rising levels of human capital per capita could make the average individual better at discovering and sharing ideas. As was the case in OECD [Organisation for Economic Co-operation and Development] countries in the second half of the twentieth century, if new institutions change incentives, the fraction of the available human capital that is devoted to producing and sharing ideas could continue to rise. To that end, there is enormous potential for similar economic and innovation-driven transformation in countries like China and India. It is possible even that growth at the technological frontier could continue for the foreseeable future, and who knows, it might even increase again in this century compared to the last (Jones and Romer 2010: 235).

For China, in particular, capital per worker must rise in the new phase of its development. An effective way of preventing diminishing returns to capital is to increase China's human capital per worker, which could sustain a continual improvement in productivity. Towards that goal, China may benefit from its unusual workforce structure, in which human capital is highly skewed in favour of younger workers. This offers an implicit new productivity potential that structurally is not open to economies where the human capital of older workers is closer to that of younger workforce entrants.

In its review of educational priorities for China in the coming century, the World Bank (1999: 9; see also 2013) reinforces both the positive correlation between education and economic growth and the increasing relevance of education:

That link is strengthening with increasing globalization, competition for markets and dependence of economies on knowledge and information. Skill is replacing other factors as a basis for competitive advantage in the global economy; the economic strength of a nation will become more dependent upon its ability to develop, utilize and manage its human resources. 
Continuous improvement in productivity is expected to become the primary mechanism by which Chinese authorities can promote economic growth in the next century. Education has played an important role in China's economic growth through the reform period. Changes in government education policy have brought rapid change in tertiary education (Figure 1.8), and the share of education expenditure in GDP has been rising in recent years, even approaching the level of developed countries (Figure 1.9). According to Jones and Romer (2010: 241), '[t] he rising supply of highly educated labour tilts technical change in its own direction'.

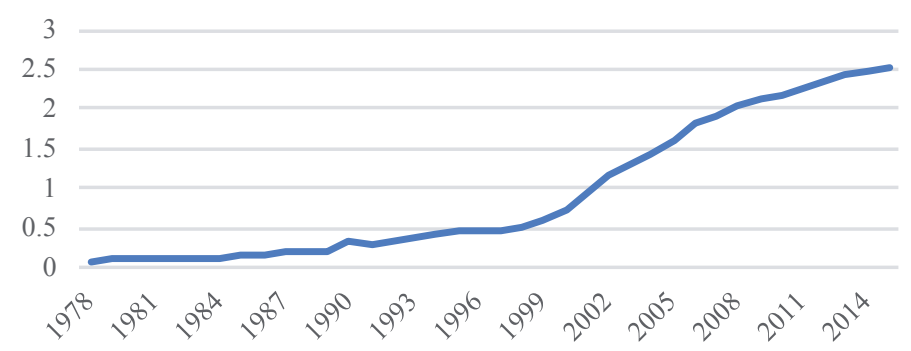

Figure 1.8 University students per 100 population, 1978-2014 Source: NBS (various years).

Nonetheless, China must do more to improve the quality of education at all levels and also to create an environment in which human capital investment is duly recognised and respected. In the university sector, through projects such as Project 985 and 211, China has, for two decades, invested heavily in ensuring that the country is home to some world-class universities. Peking University and Tsinghua University are now ranked in the top 100 universities worldwide, at 29 and 35, respectively, according to the 2017 Times Higher Education World University rankings. Continued investments in this direction are crucial if China is to become a more innovative and productive economy and society.

Harnessing the benefits of rising human capital through improved institutions (and, thereby, incentives) is another key to sustaining China's future economic growth, including its contribution to future global growth and wellbeing (Glazebrook and Song 2013).

\section{Innovation and technology}

The economic growth literature of the past half-century has identified the importance of technological change. Invention and innovation are the sources of technological change and can create knowledge that might spill over to entities that were not responsible for the original creation (Hall and Rosenberg 2010: 6). This suggests a need for policy to encourage the appropriate level of investment in these activities (Arrow 1962). 
To encourage innovation, the Chinese Government and Chinese industrial enterprises have invested more and more in research and development (R\&D) (Figure 1.9).

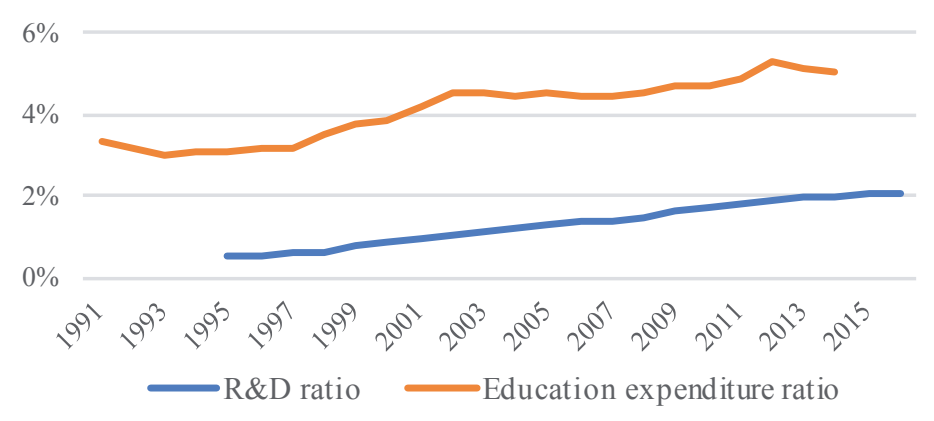

Figure 1.9 China's shares of R\&D and total education expenditure in GDP, 1991-2015

Source: NBS (various years).

Technological change has been accelerating in several key sectors, including transport, space technologies and telecommunications. Increased competition, government subsidises and the chance to learn from frontier markets abroad through opening up and reform have supported that process. Contributing factors include collaboration between firms and scientific and research institutions, including universities, and the strengthening of incentives (Figure 1.10).

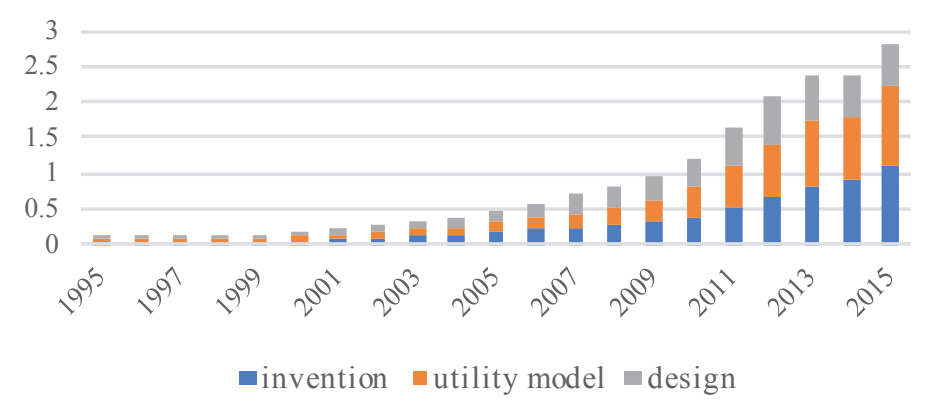

Figure 1.10 Number of patent applications, 1995-2015 (million)

Source: NBS (various years).

Such efforts are intended to support technological development in China while also enabling continuous learning from other countries. The goal is for China to contribute increasingly to extending the global technological frontiers.

Nurturing private entrepreneurship is important in that context. Enhancing competition and improving the productive use of resources can be supported by lowering and removing entry barriers to private enterprises in industries providing essential services to growing industries—particularly financial and banking services. 
The increased participation of private firms in service industries will also improve private sector access to resources, especially capital and credit, which are critical for private sector innovation and development.

Government policy and regulation seeking to advance the role of the private sector in the allocation of key resources can drive increasing productivity in China (Son and Song 2015).

Finding ways to increase the efficiency and effectiveness of R\&D expenditure is an important concern, for governments and entrepreneurs alike.

We are living in a new era when modern technologies are increasingly affecting all aspects of our life. China is making great efforts to embrace these new developments across the entire country, but faces tremendous challenges. This 2017 volume is an attempt to contribute deeper analysis of the role of human capital, innovation and technological change in a transitional economy and to discuss ways in which China's experience has offered some important lessons for China itself and for other countries, too.

\section{Structure of the book}

\section{Part I: Reform and macroeconomic development}

Four chapters provide perspectives on recent macroeconomic developments in China. First, Cai and Zhang (Chapter 2) explain the additional reform challenges of China's 'new normal' growth era. Thereafter, Huang et al. (Chapter 3) explain the official goal of 'making progress while maintaining stability'. The authors outline a new economy index that helps to measure 'progress' and draw attention to issues of stability, especially in the financial sector. Yao and Wang (Chapter 4) estimate the potential for a successful process of internal convergence to sustain China's longrun growth. Woo (Chapter 5) rounds out the first section by bridging the domestic 'new normal' and the more recent 'international new normal' arising from the election of US President Donald Trump and the Brexit transition.

Cai and Zhang (Chapter 2) elaborate China's new and ongoing policy changes in the 'new normal' era of slower growth. They note that reform is now more difficult, especially since many necessary reforms have shifted from being characterised by 'Pareto improvement' - in which the majority of people benefit and no one suffers - to 'Kaldor improvement', which requires a balance to be struck between the winners and losers from reform. Key areas of reform within that challenging context therefore include legal and property rights protection reforms, a shift from industrial to competition policy and optimising the roles of the market and government in 
deciding the allocation of resources. The authors note that defining boundaries for the market and government is a practical matter and that, during a catch-up phase, distortions in that balance may be more pronounced. Compared with the states of other major economies, the Chinese Government owns a relatively high share of the national wealth. Towards reforming the incentive mechanism, policymakers must now much better understand the benefits or costs associated with reform and work to reach consensus on the direction of the roadmap across government and society. This will not only better support greater competition and entrepreneurship, but also ensure collective support for an ongoing and deeper reform process.

Huang et al. (Chapter 3) explain how the combination of slowing growth and financial risk led the December 2016 Central Economic Work Conference and the more recent National People's Congress (NPC) meetings to decide on an economic policy goal of 'making progress while maintaining stability'. This means a proactive fiscal policy with prudent monetary policy, increasing exchange rate flexibility while retaining basic exchange stability and resolving systemic risk as macroeconomic policy priorities. In this chapter, the recent rise in economic momentum is attributed to cyclical factors, including public infrastructure spending, implying uncertainty for the medium term. The cause of that broader slowdown and transition uncertainty relates to the fact that earlier growth-driving industries have lost competitiveness, but new ones have not replaced them. An index of the new economy composed and elaborated on in Chapter 3 finds that the new economy accounts for about 30 per cent of the total economy at the moment. As a greater share of resources shift into the new-economy sector, the identified crowding-out effect of the relatively high share of investment currently going to old-economy sectors will diminish and will, in turn, help to ensure a sustainable growth path. Over time, this may also serve to directly and indirectly facilitate a smoother regional progression towards the new economy. At present, southeastern China is ahead of the rest of the country in that transition. Overall, such progress will also reduce systemic financial risk, which probably relates to slow growth, high leveraging, low productivity and limited policy flexibility.

Yao and Wang (Chapter 4) examine how internal convergence-regional, efficiency and technological-can sustain China's long-run growth. The authors estimate growth equations for China's three geographic regions and for the whole country, finding different speeds of regional convergence, different levels of investment efficiency and different speeds of technological progress in the three regions. The authors calculate that regional convergence in China could offer a growth dividend of almost 12 per cent, technological convergence could increase China's growth potential by one-third and convergence of investment efficiency in the two inland regions towards that of the eastern region would not have a large effect on the level or rate of growth. 
There are, however, a number of obstacles to realising these potential growth gains: it is difficult to attract talent to China's lesser-developed inland regions and the persistence of structural challenges such as the issue of zombie firms. Removing these obstacles would add momentum for economic convergence.

In a year of conflicting signals for China's economy, Woo (Chapter 5) completes part one with a study of three important economic issues for China: the current trajectory of the economy, the policy options to influence that trajectory and some possible additional elements to be incorporated into international economic relations. He specifically takes on conflicting interpretations of China's economic challenges, especially the difference between optimists and pessimists. Adopting a new framework classifying China's policy challenges-into 'hardware' and 'software' categories — the author proposes a reform agenda that will also help China to avoid underlying 'power failure'. This includes structural reforms to rationalise the state-owned enterprise (SOE) sector, deregulation of markets for capital, labour and land and structural reform of governance institutions such as the bukou household registration system and rural landownership. In addition, in the context of the 'new international normal' - the absence of hegemonic stability - the author argues China should now more actively shape globalisation in such ways as to expand on former Chinese president Hu Jintao's notion of a 'harmonious' society and transform it into a concept of a 'harmonious world'.

\section{Part II: Education and human capital}

Education provides the building blocks for the accumulation of human capital. China's progress in accumulating human capital and trends in capturing the benefits of such productive capacity over time have been mixed. Part two looks at two elements of that story. First, Golley and Kong (Chapter 6) compare the educational outcomes of Chinese citizens born over five decades after 1940 and identify a number of factors that have served to undermine equal opportunity in China's education system over time. Second, Yang and Zhou (Chapter 7) use China's input-output table to study the role of intangible capital in the country by industrial sector.

Golley and Kong (Chapter 6) show that China's workforce is, on average, poorly educated compared with an OECD average benchmark. Against that backdrop and China's aspiration to close the gap between the domestic and frontier economies, the authors study the educational outcomes of Chinese citizens born over the halfcentury from 1940 with a focus on whether gaps were driven by inequality of opportunity'. Data from the China Family Panel Studies (CFPS) provide years of schooling for rural and urban population samples. After identifying the key determinants of educational outcomes_-among which are China's hukou system, paternal education levels and birth cohort-the authors calculate the share of 'inequality of opportunity' in overall educational inequality. They conclude with 
a call for policies to reduce the impact of factors exaggerating educational inequality in China, especially in light of China's attempt to transition towards a higher valueadded and innovative economy.

Yang and Zhou (Chapter 7) utilise data from China's input-output tables to study the role of intangible capital by industrial sector. In the process, the authors also offer a new methodology for measuring the role of intangible capital for economies with poor data. The authors find that growth in intangible capital can explain almost 20 per cent of the TFP growth over the period 1997-2012. This result is robust under various forms of sensitivity analysis. At the sector level, R\&D is found to play a more important role in agriculture than economic competency and computerised information; but the role of economic competency is more important in the services and light industry sectors than that of $\mathrm{R} \& \mathrm{D}$ and computerised information.

\section{Part III: Innovation and productivity}

Part III explores in greater detail China's transition towards a more innovative economy. First, Wei et al. (Chapter 8) uses firm-level data to find that, despite being at a disadvantage in competing for funds with the state sector, private firms embracing international markets and finding creative ways to adapt to rising labour costs are pushing the frontier of China's transition up the productivity and manufacturing value chains. Wu et al. (Chapter 9) present new estimates of China's productivity growth rates by province. They find productivity gains are now consistently higher in inland areas than coastal areas, and that services sector growth in coastal areas is promisingly robust and thus may be able to sustain growth in these areas in future.

Yang et al. (Chapter 10) find that regional innovation capacity is playing a role in determining the rate of regional convergence in China and argue that this must be accounted for in China's policies to reduce regional economic inequalities.

Yin and Mao (Chapter 11) study firm-level patent-seeking and its impact on R\&D expenditure. They find that both market-driven patent-seeking and the number of patents held are among factors associated with higher levels of R\&D activity among firms.

Finally, Krolikowski (Chapter 12) explores the cultural habits and industrial progress of China's frontier aeronautical and space research communities.

Wei et al. (Chapter 8) open with a reminder of the scale of China's demographic challenge. After more than three decades of high growth based on exploitation of demographic and wage cost advantages, interacting with international and marketoriented reforms, China now confronts higher wages and a shrinking workforce. Future growth now must depend more on innovation and increased productivity. Chapter 8 assesses the likelihood of China making the transition. It uses matched 
firm-level data on patent applications, receipts and citations and a survey of manufacturing firms. It finds that embracing new international opportunities and adapting to rising labour costs are two factors leading China's increasingly innovative economy. A result is that the quality of Chinese exports is increasing, but there is also evidence of resource misallocation affecting innovation: state-owned firms receive a greater share of innovation subsidies, but private firms are more successful innovators. The authors argue that the transition to an innovation-led economy will progress more quickly if this resource misallocation can be tackled.

In Chapter 9, Wu et al. note that the greater importance of innovation and entrepreneurship as new drivers of China's economy has led to an intense debate about the role and dynamics of productivity growth in China. The authors present an update on this area of the literature. Most studies agree that while TFP made a significant and positive contribution to China's economic growth in recent decades, both TFP and economic growth rates in China have slowed in recent years. Whether this downward trend continues has important implications for China's economic development. Somewhat optimistically, new estimates presented here find that China's inland regions have maintained high growth and have outperformed coastal regions across all sectors: primary, manufacturing and services. Whereas manufacturing TFP in coastal areas has suffered in recent times, services sector TFP growth in coastal China is robust and could thus help to sustain growth in these regions into the future.

Yang et al. (Chapter 10) offer an empirical analysis of the convergence of real GDP per capita of 31 Chinese provinces and municipalities over the period 2001-15. They explore the impact of innovation capability on economic convergence and identify three key results: 1) after considering the spatial effect, China's regional economic development has both conditional convergence and absolute convergence; 2) the trend towards regional economic development convergence is increasing; and 3) after regional innovation capacity is taken into account, the convergence speed of China's regional economy will deteriorate. In other words, innovation ability has a significant effect on the speed of economic convergence. In turn, if the excessive concentration of innovation resources along China's coastal region is not better spread across the country, China's economic development will experience innovation-led regional divergence. In formulating innovation policy, the government should thus pay attention to spatial interaction.

In Chapter 11, Yin and Mao use data from the 2013 National Patent Survey to study the causal relationship between Chinese patent protection and enterprise R\&D expenditure, and the more specific effects on promoting R\&D of patent motivation (e.g. protection of inventions and strategic blocking behaviour), accumulation and choice of protection model. The findings include patent filing is market-driven and closely associated with $\mathrm{R} \& \mathrm{D}$ expenditure, firms that hold a higher number of patents on average spend more on $R \& D$ and the type of 
patents held (patent quality) is not significantly associated with R\&D expenditure. Since patent motivation has an important impact on consequential innovation, the chapter concludes that Chinese policymakers should pay attention to patent motivation when incentivising innovators and, similarly, that both firms and the state, if relevant, should encourage patent quality over quantity. Finally, China's unique 'double-track' judicial and administrative patent rights enforcement and protection mechanism should be strengthened.

Krolikowski (Chapter 12) offers a fascinating introduction to what is possibly the world's most rapidly advancing space program. Moreover, China is also poised to enter the technologically demanding large-carrier segment of the global aircraft industry. Within that dynamic system, Chapter 12 informs us how these particular scientific expert clusters share specialised knowledge and culture. They are also concentrated in two large state-owned defence-industry groups-the Chinese Aerospace Science and Technology Corporation (CASC) and the Chinese Aerospace Science and Industry Corporation (CASIC) — several government agencies, military organs and technical universities and research institutes. Their culture over time has become more meritocratic, but these agencies and areas of expertise in general remain relatively insular. They do, however, have a unique role to play in shaping China's innovation policy, especially the long-term ideal of national control over satellite and launch vehicle manufacture. Understanding the cultures and hierarchies of these scientific communities and their interrelationships with policymakers and national goals can shed light on China's progress towards the high-tech frontiers of the aerospace sector.

\section{Part IV: Technological change by sectors}

Technological change within key economic sectors lies at the heart of a bigger story of transformation. Part IV comprises three chapters that study one topic from each of the primary, secondary and tertiary sectors.

Sheng et al. (Chapter 13) present an interesting idea for deepening the mechanisation of China's agricultural sector and raising productivity levels without increasing average farm size. Jiang (Chapter 14) looks at renewable energy technologies and presents a thorough review of industrial structure and progress for hydropower, wind, solar and biomass energy. Kendell and Lees (Chapter 15) round out Part IV with an exploration of frontier financing in China. They demonstrate the dexterity of China's financial policymakers in recently advancing China's 'repo' markets as an additional and increasingly important source of shorter-term financing in the country. 
Sheng et al. (Chapter 13) tackle a longstanding constraint to the productivity growth of agricultural production in developing countries: small farm size. The authors argue that, in place of agglomerating small farms into larger ones, contract mechanisation services (in particular, capital outsourcing) could offer an alternative route to increasing farm productivity. This, in turn, can raise the capital-labour ratio of medium-sized and small farms, complementing earlier Chinese land consolidation reform towards continued improvement in industry-level agricultural productivity. Such institutional creativity could offer China's small farming households the opportunity to continue to increase productivity via 'increasing returns to scale' and frontier technologies_-without having to make prohibitively large investments. However, they point out that market-based outsourced mechanisation services are constrained by market friction, high transaction costs and various institutional barriers. Institutional innovation is therefore required to reduce market transaction costs to facilitate the use of outsourced mechanisation services to deal with the issue of small farm size in agricultural production along with land consolidation reform.

In Chapter 14, Jiang sheds light on China as a leading player in renewable energy development. Renewable energy capacity in China accounts for some one-third of the global total, and growth in the industry has been especially strong since 2011 . Growth has been especially rapid in solar, which has grown by 110 per cent per annum over this period. Strong policy support has led to technological progress and large falls in prices. Chapter 14 describes these trends, especially with respect to developments in hydro, wind, solar and biomass power capacity and industrial development in China. Chinese authorities are committed to reaching the climate change-related targets of the Paris agreement. The author highlights that China reaching its energy transition and clean air targets are central to the realisation of international climate change goals.

Kendell and Lees (Chapter 15) explore the market for repurchase agreements ('repo'), which are an important source of short-term funding for financial institutions operating in China. Used by the People's Bank of China to manage domestic liquidity conditions through open market operations, repos are likely to become increasingly important as a channel for the transmission of monetary policy. The authors describe the characteristics of China's repo market. They initially focus on the interbank market and then look at recent developments and their impact on the bond market. They show that lower and less volatile repo rates over the past couple of years have contributed to greater risk-taking in financial markets and policy settings in China have been dynamic in shaping and responding to these developments. 


\section{Part V: Technologies with trade and investment}

Part V explores China's progress in innovation in trade, investment and development finance globally. First, Athukorala (Chapter 16) studies China's trade balances in terms of the evolution of East Asian production networks and, despite views being trumpeted internationally, the chapter suggests that punitive tariffs against China may, paradoxically, hurt competing international business interests more than those in China. Chen (Chapter 17) studies empirically the impact of China's outward foreign direct investment (OFDI) on its economic growth by using a province-level panel dataset covering 30 provinces and the period 2004-14.

The final two chapters of the 2017 volume elaborate issues that are important to China's prominent 'One Belt, One Road' initiative and its new globalisation push. $\mathrm{Hu}$ et al. (Chapter 18) study existing economic patterns and make suggestions for policies that will deepen ties between China and a section of the 'Road': the five countries of the Eurasian Economic Union (EEU). Johnston and Rudyak (Chapter 19) make an important contribution in the context of China's new globalisation. They identify political and economic points of inflection and influences that shaped China's own globalisation as a means to understanding how China may shape globalisation itself.

In Chapter 16, Athukorala explores the implications of China's evolving role in East Asian global production networks. The context of the chapter is increasing recent international trade friction and the role of regional and international production networks. He argues that China's widening trade imbalances with many economies are a structural phenomenon driven by a process of global production sharing and the decades-deep pivotal role played by China within East Asian-centred global production networks. Global production sharing is an integral part of economic globalisation, so the underlying story of the US-Sino trade gap is more complicated than can be revealed by standard trade-flow analysis. China's final assembly export networks are not only extensive across East Asia and the Organisation for Economic Co-operation and Development (OECD), but also extend increasingly to Africa, Latin America and the Middle East. As a result, punitive tariffs on China are bound to face opposition from American business interests and the impact on global production network flows may be less damaging than is commonly thought.

Chen (Chapter 17) finds that both OFDI from provincial firms and OFDI from central government-controlled state-owned enterprises ( $\mathrm{SOEs}$ ) have a statistically significant positive impact on China's provincial economic growth. The positive impact of OFDI on provincial economic growth may be the result of reverse knowledge spillovers from OFDI to the home province's economy through demonstration and imitation, labour movement, backward and forward industrial linkages, information flows, promoting the exports of local firms and facilitating industrial restructuring and technological upgrading of home economies, 
thus increasing the productivity and efficiency of local firms and promoting growth of the home economy. Overall, the study offers strong empirical evidence that OFDI contributes to China's economic growth. Policies should aim to develop a more open and market-oriented OFDI regime, encourage R\&D and technological development to increase the ownership advantages of home-economy domestic firms and encourage interaction between home-economy multinational enterprises (MNEs) and home-economy domestic firms to enhance and accelerate the diffusion of positive reverse knowledge spillovers from OFDI to China's economy.

$\mathrm{Hu}$ et al. in Chapter 18 explore ' $5+1$ ' cooperation between China and the five countries of the EEU: Russia, Belarus, Kazakhstan, Kyrgyzstan and Armenia. These countries are central to the 'Belt' in China's 'One Belt, One Road' initiative. The authors compare resource endowments in China and EEU countries and examine the potential for greater mutual and global connectivity around infrastructure investment, as well as deeper trade and investment ties. The authors make a series of policy suggestions to foster greater collaboration between China and the five EEU countries. These include encouraging greater financial integration-directly through the establishment of Chinese financial institutions in the five EEU countries and indirectly through expanding funding levels and mechanisms for development projects. Similarly, greater use of the renminbi within the region may reduce currency instability, which recently has been an issue. Away from finance, the authors suggest more visa-free mobility and enhanced trade and industrial policy coordination as mechanisms for facilitating greater economic activity among member countries.

Johnston and Rudyak (Chapter 19) bring the 2017 volume to a close with their chapter on one of the most important features of China's new globalisation agenda: foreign aid and development finance. In his plenary speech to the World Economic Forum in Davos in early 2017, the Chinese President Xi Jinping noted that China should 'adapt to and guide economic globalization, cushion its negative impact, and deliver its benefits to all countries and all nations'. With the stated goal of China playing a greater leadership role in globalisation, including through delivering benefits to other developing countries, $\mathrm{Xi}$ drew attention to the role of China's foreign aid in contributing to global growth. Since understanding China's own experience with foreign aid could shed light on the potential directions of its new globalisation agenda, the authors present a chronology that helps explain how and why China may now develop its own economic interests and those of other developing countries by being more active in shaping globalisation. Africa has been an especially important focus of China's aid policy, since half of China's foreign aid to Africa is also a focus of the 'One Belt, One Road' initiative. 


\section{References}

Arrow, K. (1962), Economic welfare and the allocation of resources for invention, in R. R. Nelson (ed.), The Rate and Direction of Inventive Activity, pp. 609-26, Princeton, NJ: Princeton University Press. doi.org/10.1515/9781400879762-024.

The Conference Board (2015), The Conference Board Total Economy Database, New York: The Conference Board. Available from: www.conference-board.org/ data/economydatabase/.

Dosi, G. and Nelson, R. R. (2010), Technical change and industrial dynamics as evolutionary processes, in B. H. Hall and N. Rosenberg (eds), Handbook of the Economics of Innovation: Volume 1, Amsterdam: Elsevier. doi.org/10.1016/ S0169-7218(10)01003-8.

Eichengreen, B., Park, D. and Shin, K. (2013), Growth slowdowns redux: New evidence on the middle-income trap, NBER Working Paper No. w18673, National Bureau of Economic Research, Cambridge, Mass.

Glazebrook, K. and Song, L. (2013), Is China up to the test? A review of theories and priorities for education investment for a modern China, China \& World Economy 21(4): 56-78. doi.org/10.1111/j.1749-124x.2013.12028.x.

Hall, B. H. and Rosenberg, N. (2010), Introduction to the handbook, in B. H. Hall and N. Rosenberg (eds), Handbook of the Economics of Innovation: Volume 1, pp. 3-9, Amsterdam: Elsevier. doi.org/10.1016/S0169-7218(10)01001-4.

Jones, C. I. and Romer, P. M. (2010), The new Kaldor facts: Ideas, institutions, population, and human capital, American Economic Journal: Macroeconomics 2(1): 224-45. doi.org/10.1257/mac.2.1.224.

Maddison, A. (1982), Phases of Capitalist Development, Oxford: Oxford University Press.

National Bureau of Statistics of China (NBS) (various years), China Statistical Yearbook, Beijing: China Statistics Press.

Son, N. C. and Song, L. (2015), Promoting private entrepreneurship for deepening market reform in China: A resource allocation perspective, China \& World Economy 23(1): 747-77.

Thirlwall, A. P. and Pacheco-Lopez, P. (2017), Economics of Development: Theory and evidence, London: Palgrave Macmillan. doi.org/10.1057/978-1-137-57795-5. 
World Bank (1999), Strategic goals for Chinese education in the 21st century, Report No. 18969-CHA, The World Bank, Washington, DC. Available from: documents.worldbank.org/curated/en/203951468768863829/Strategic-goalsfor-Chinese-education-in-the-21st-century.

World Bank (2013), China 2030: Building a modern, harmonious, and creative society, Report No. 76299, The World Bank, Washington, DC. Available from: documents.worldbank.org/curated/en/781101468239669951/China-2030building-a-modern-harmonious-and-creative-society. 
This text is taken from China's New Sources of Economic Growth: Human Capital, Innovation and Technological Change, Volume 2, edited by Ligang Song, Ross Garnaut, Cai Fang and Lauren Johnston, published 2017 by ANU Press, The Australian National University, Canberra, Australia.

dx.doi.org/10.22459/CNSEG.07.2017.01 